\title{
Long term improvement in global left ventricular function after early thrombolytic treatment in acute myocardial infarction Report of a randomised multicentre trial of intracoronary streptokinase in acute myocardial infarction
}

\author{
JAN C J RES, MAARTEN L SIMOONS, ERNST E VAN DER WALL, \\ MACHIEL J VAN EENIGE, FRANK VERMEER, FREEK W A VERHEUGT, \\ WILLIAM WIJNS, SIMON BRAAT, WILLEM J REMME, \\ PATRICK W SERRUYS, JAN P ROOS \\ Working Group on thrombolytic therapy in acute myocardial infarction of the Interuniversity Cardiology \\ Institute, the Netherlands $\star$
}

SUMMARY The effect of reperfusion achieved by early intracoronary streptokinase in acute myocardial infarction on left ventricular function was studied in 533 patients enrolled in a prospective randomised multicentre study. Two hundred and sixty four patients were allocated to conventional treatment and 269 patients to thrombolysis. At the end of the procedure patency of the infarct related vessel was achieved in $198(85 \%)$ of 234 patients in whom coronary angiography was performed. The median interval from onset of symptoms till the angiographic documentation of patency was 200 minutes. Data were analysed according to the original treatment allocation. Global left ventricular ejection fraction was determined by radionuclide angiography in 418 patients within two days of admission, in 361 patients after two weeks, and in 307 patients after three months. Global left ventricular function remained unchanged throughout the observation period in the control group, whereas it improved during the first two weeks in patients allocated to thrombolytic treatment. Improved function in these patients persisted up to three months after the infarction. Global left ventricular ejection fraction was significantly better in the thrombolysis group than in the control group at two days, two weeks, and at three months. In patients with anterior myocardial infarction the left ventricular ejection fraction was $9 \%$ better than in the control group at two weeks and at three months. In the patients with inferior myocardial infarction differences between the two treatment groups were smaller because of photon attenuation within the body. Angiographic evidence suggested that the improvement in function seen after thrombolysis is indeed associated with the patency of the infarct related artery.

^Participating centres and collaborators: Thoraxcenter, Erasmus University and University Hospital Dijkzigt, Rotterdam (M J B M vd Brand, P J de Feyter, P Fioretti, P G Hugenholtz, P W Serruys, M L Simoons, W Wijns); Department of Cardiology, Free University, Amsterdam (M J van Eenige, J C J Res, J P Roos, F W A Verheugt, F C Visser, E E vd Wall); Department of Cardiology, Zuiderziekenhuis, Rotterdam (D C A van Hoogenhuyze, X H Krauss, H A C M Kruyssen, W J Remme, C J Storm); Department of Cardiology, St Annadal Hospital, Maastricht (F W H M Bär, S H J G Braat, P Brugada, $K$ den Dulk, $W$ T Hermens, $H$ J J Wellens, G M Willems, C de Zwaan); Department of Cardiology,
University Hospital, Leiden (B Buis, J G Engbers, A vd Laarse, E E vd Wall,); Data processing centre ( $S$ vd Does, $R T$ van Domburg, $M$ Koelemay, A J P Karreman, J Lubsen, J P van Mantgem, K J de Neef, J Planellas, F Vermeer, A A Wagenaar, I C J Zorn).

Requests for reprints to Dr Jan C J Res, Department of Cardiology, Free University Hospital, De Boelelaan 1117, 1007 MB Amsterdam, the Netherlands.

Accepted for publication 17 June 1986 
In approximately $80 \%$ of patients with acute myocardial infarction, recanalisation of the infarct related coronary artery, which is usually occluded, can be achieved by intracoronary administration of streptokinase. Although data from earlier small randomised trials were inconclusive, ${ }^{1-7}$ the trial conducted by the Netherlands Interuniversity Cardiology Institute showed that recanalisation, which was achieved in $85 \%$ of patients, reduced by $30 \%$ the infarct size as estimated by myocardial enzyme release, preserved global left ventricular function as measured by contrast angiography, and improved one year survival. ${ }^{8-10}$ In addition to these measurements, radionuclide angiography was performed early after admission, at the time of hospital discharge, and after three months. These radionuclide studies demonstrated that the beneficial effects of thrombolytic treatment on left ventricular ejection fraction persisted for at least three months.

\section{Patient selection and study protocol}

From June 1981 till March 1985, 533 patients were enrolled at five hospitals in a trial to compare conventional treatment and a strategy aimed at early recanalisation by intracoronary administration of streptokinase. Patient selection, study protocol, and procedures have been described in detail. ${ }^{8-12}$ Briefly, patients under 71 years of age who had typical chest pain for $>20$ minutes and electrocardiographic signs of myocardial infarction were eligible for this trial if they were admitted to the coronary care unit within four hours of the onset of chest pain. Exclusion criteria were: previous treatment with streptokinase or bypass surgery of the infarct related vessel, a high risk for bleeding such as recent trauma, traumatic resuscitation, haematuria, and pregnancy or inability to give informed consent.

Patients were randomly allocated to thrombolysis or conventional treatment. Only patients allocated to thrombolytic treatment were asked for informed consent. ${ }^{13}$

Patients were given intravenous heparin $(5000 \mathrm{U})$, $100 \mathrm{mg}$ prednisolone, and $250 \mathrm{mg}$ acetylsalicylic acid before angiography. Lignocaine $(200 \mathrm{mg} / \mathrm{min})$ and intravenous glyceryl trinitrate were also given. After visualisation of the infarct related vessel, intracoronary streptokinase was given at a rate of $4000 \mathrm{IU}$ per minute till reperfusion was achieved or until the clot was completely lysed. Usually a maximum dose of $250000 \mathrm{IU}$ was administered. Patients with initially incomplete obstruction were given streptokinase for at least 15 minutes. From January 1984, after it had become apparent that preparation of the catheterisation laboratory delayed the intracoronary streptokinase infusion by about an hour and that intravenous streptokinase treatment produced patency of about $50 \%$ of vessel, ${ }^{14}{ }^{15}$ we decided to start thrombolytic treatment in the coronary care unit immediately after informed consent had been obtained. Since then 500000 units of streptokinase have been infused over 10 to 20 minutes. Patients who refused thrombolytic treatment and those who were unsuitable for such treatment were given conventional treatment. ${ }^{16}$ Treatment with full dose intravenous heparin was started and anticoagulation was continued with coumadin until hospital discharge. ${ }^{17}$ Coronary angiography and contrast ventriculography were performed two to six weeks after admission.

\section{RADIONUCLIDE ANGIOGRAPHY}

Gated equilibrium radionuclide angiography was performed between the first and the third day after admission with a gamma camera (Cardiac camera, Siemens Gammasonics; Philips P 855 M; or Medical Data Systems-A2). Red blood cells were labelled in vivo with pyrophosphate and then with $15 \mathrm{mCi}$ $(555 \mathrm{MBq})$ of technetium-99m. Angiograms were obtained 10 minutes after injection. An approximately $45^{\circ}$ left anterior oblique view with a $10^{\circ}$ cranial tilt was selected to give the best separation of the left and right ventricles. A low energy, all purpose collimator was used. A $20 \%$ window was set symmetrically around the $140 \mathrm{keV}$ gamma peak and data were collected in a matrix of $64 \times 64$ pixels. Gating at 20 frames per cycle was used. Data were acquired over six minutes and stored on disc. Global left ventricular ejection fraction was computed by means of an automated edge detection program which has the advantage of a low operator interaction and a good reproducibility ${ }^{18}$ or with the commercially available software of the MDS or Philips systems. ${ }^{19}$ With both systems we used a dual, variable region of interest technique with background subtraction.

The radionuclide angiography study was repeated with the same system before hospital discharge and three months after the acute event. The studies were evaluated without knowledge of the patient's identity or treatment. Serial concentrations of $\alpha$-hydroxybutyrate dehydrogenase (HBDH) or lactate dehydrogenase ( $\mathrm{LDH}$ ) levels were measured to estimate the infarct size. ${ }^{90}$

\section{DATA ANALYSIS}

The data were analysed according to the original treatment allocation. Furthermore, the effect of thrombolysis on left ventricular function was studied in subsets of patients determined by infarct site and previous history. The ejection fraction data are given as means (SD). Student's $t$ test was used for comparisons between groups and data within indi- 
vidual groups were compared by the paired $t$ test. Frequency distributions were compared by the $\chi^{2}$ test or the Mann-Whitney test. Two tailed $p$ values $<0.1$ are reported and $p$ values $<0.05$ were regarded as significant.

\section{Results}

Two hundred and sixty four of the 533 patients were assigned to conventional treatment and 269 patients to thrombolysis-152 to intracoronary streptokinase and 117 to intravenous streptokinase immediately followed by intracoronary thrombolytic treatment. The median interval between onset of symptoms and admission to the coronary care unit was 90 minutes. ${ }^{8}$ Thirty five patients who had been allocated to thrombolysis did not receive this treatment because they refused it ( 20 patients), because it failed to reach the coronary artery (6 patients), because of early death (one patient), because of contraindications detected after randomisation (3 patients), or because the chest pain resolved and the electrocardiogram became normal shortly after randomisation (5 patients). ${ }^{8}$ Two hundred and thirty four patients had coronary angiography and 65 patients, of whom 40 had received intravenous streptokinase, showed a patent infarct related vessel at the first angiogram. Recanalisation of the occluded vessels was achieved in $133(79 \%)$ of 169 patients. In $198(85 \%)$ of 234 patients the infarct related vessel was patent at the end of the procedure.
The median interval from the onset of symptoms to angiographic imaging of a patent infarct related vessel was $\mathbf{2 0 0}$ minutes. Forty six patients in the thrombolysis group had percutaneous transmural coronary angioplasty in the acute phase as part of the recanalisation procedure.

The first radionuclide angiographic study was performed on 418 patients, the second study before hospital discharge on 361 patients, and a third study at three months follow up on 307 patients. In some patients radionuclide angiograms were not obtained because they had died, had had bypass surgery or recurrent myocardial infarction, or had refused to participate in further studies. Table 1 shows that the baseline characteristics and the infarct size determined by cumulative $\alpha$-hydroxybutyrate release were similar in the randomised group of patients and in the subgroups with early and late radionuclide angiograms. There were no baseline differences between patients allocated to conventional treatment and those allocated to thrombolysis.

The left ventricular ejection fraction measured by radionuclide angiography was greater after thrombolysis in the total population and in various subgroups after two days, two weeks, and three months (table 2); however, the variability of the measurements was considerable (fig 1). There were no changes in global left ventricular function in conventionally treated patients. In patients allocated to thrombolytic treatment there was a gradual improvement in left ventricular ejection fraction

Table 1 Baseline characteristics of all 533 patients with acute myocardial infarction in the study and of the patients who had radionuclide angiography ( $R N A)$

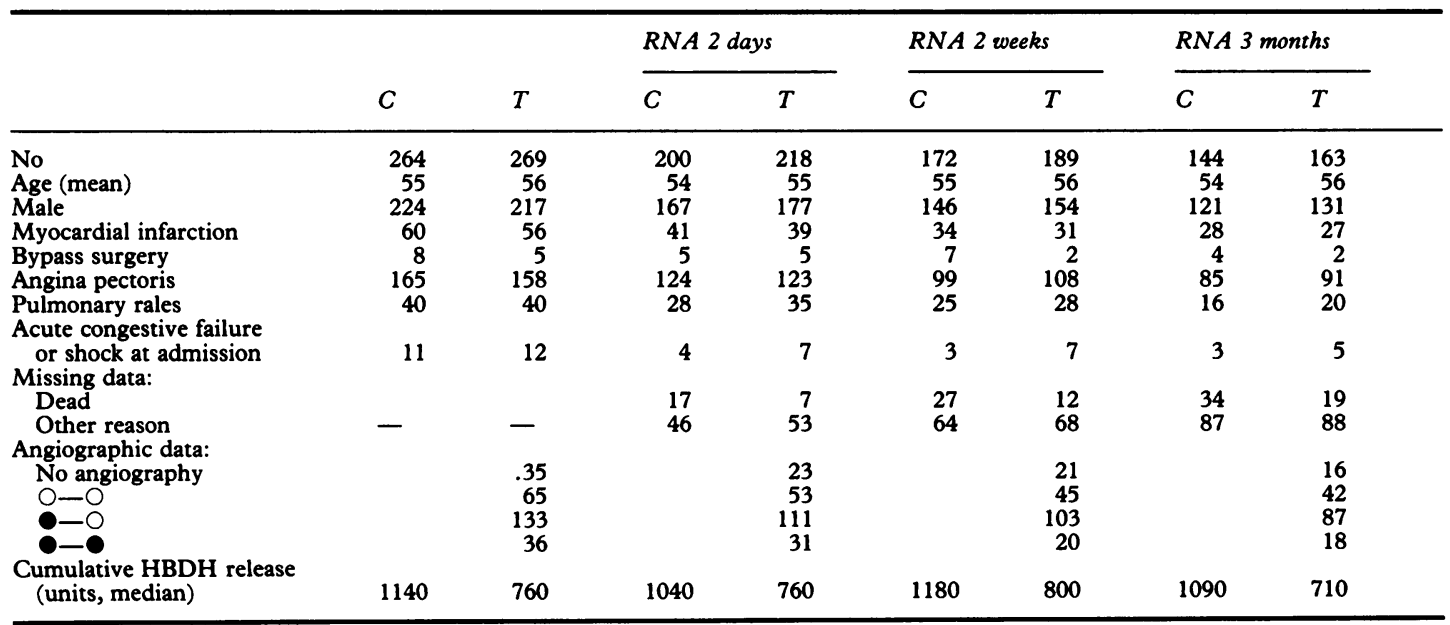

$\mathrm{O}-\mathrm{O}$, patent at first angiography with no subsequent occlusion;

- O, occluded infarct related vessel at first angiography with subsequent reperfusion;

- persistent occlusion.

$\mathrm{HBDH}, \alpha$-hydroxybutyrate dehydrogenase. 
Table 3 Change in left ventricular ejection fraction $(\triangle E F)$ in the main group and subgroups

\begin{tabular}{|c|c|c|c|c|c|c|}
\hline & \multicolumn{3}{|c|}{ Control } & \multicolumn{3}{|c|}{ Thrombolysis } \\
\hline & No & Mean (SD) & $p$ & No & Mean (SD) & $p$ \\
\hline \multicolumn{7}{|l|}{ Total: } \\
\hline$\triangle \mathrm{EF} 1$ & 141 & $0.9(11 \cdot 1)$ & NS & 161 & $3.7(9.4)$ & 0.0001 \\
\hline$\triangle$ EF 2 & 115 & $1.7(12 \cdot 5)$ & NS & 139 & $3 \cdot 6(12 \cdot 1)$ & 0.0005 \\
\hline \multicolumn{7}{|l|}{ Anterior MI: } \\
\hline$\triangle \mathrm{EF} 1$ & 58 & $1 \cdot 3(8 \cdot 7)$ & NS & 71 & $4.9(9.4)$ & 0.0001 \\
\hline \multirow{2}{*}{\multicolumn{6}{|c|}{ Inferior MI: }} & 0.002 \\
\hline$\triangle \mathrm{EF}_{1}$ & 83 & $0.7(12.6)$ & NS & 90 & & \\
\hline$\triangle \mathrm{EF} 2$ & 65 & $0.7(14.0)$ & NS & 79 & $2.3(11.4)$ & 0.08 \\
\hline \multicolumn{7}{|l|}{ First MI: } \\
\hline$\triangle \mathrm{EF}_{1}$ & 113 & $1.3(11.9)$ & NS & 137 & $3.6(9.4)$ & 0.0001 \\
\hline$\triangle E F 2$ & 93 & $2 \cdot 1(13.0)$ & NS & 117 & $3.4(11.8)$ & 0.003 \\
\hline \multicolumn{7}{|l|}{ Previous MI: } \\
\hline $\begin{array}{l}\triangle \mathrm{EF} 1 \\
\triangle \mathrm{EF} 2\end{array}$ & $\begin{array}{l}28 \\
22\end{array}$ & $\begin{array}{l}-0.5(7.3) \\
-0.1(10.5)\end{array}$ & $\begin{array}{l}\text { NS } \\
\text { NS }\end{array}$ & $\begin{array}{l}24 \\
22\end{array}$ & $\begin{array}{l}4 \cdot 4(9 \cdot 2) \\
5 \cdot 1(13 \cdot 4)\end{array}$ & $\begin{array}{l}0.03 \\
0.09\end{array}$ \\
\hline
\end{tabular}

$\triangle \mathrm{EF} 1$, change in LVEF at 2 days and 2 weeks; $\triangle \mathrm{EF} 2$, change in LVEF at 2 days and 3 months; MI, myocardial infarction.

during the first two weeks and no further changes up to three months after the infarction (table 3). Differences between the two treatment groups were most pronounced in patients with anterior wall or anteroseptal infarction, and less obvious in patients with inferior wall infarction (table 3 , figs 2 and 3). Changes in left ventricular ejection fraction between
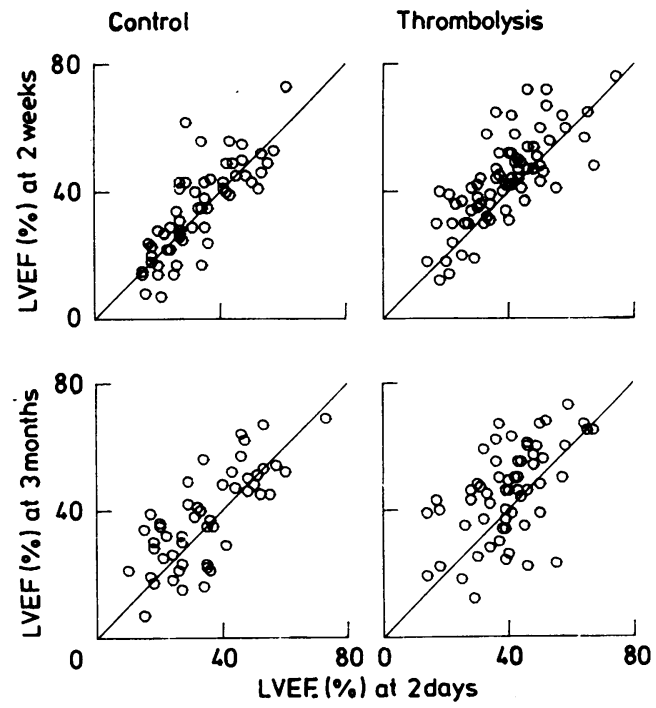

Fig 2 Paired analysis of left ventricular ejection fraction ( $L V E F$ ) at 2 days versus 2 weeks (top) and at 2 days versus 3 months (bottom) in patients with anterior wall or anteroseptal infarction who were allocated to thrombolytic treatment and in controls. The line of identity is shown in each diagram. Note a small improvement in LVEF between 2 days and respectively 2 weeks and 3 months after thrombolytic treatment. early and late measurements were similar in patients allocated to thrombolytic treatment whether or not they had had a previous myocardial infarction. The lack of statistical significance between the two treatment groups with a previous infarction was probably the result of the small numbers of patients.

An angiographic improvement in left ventricular
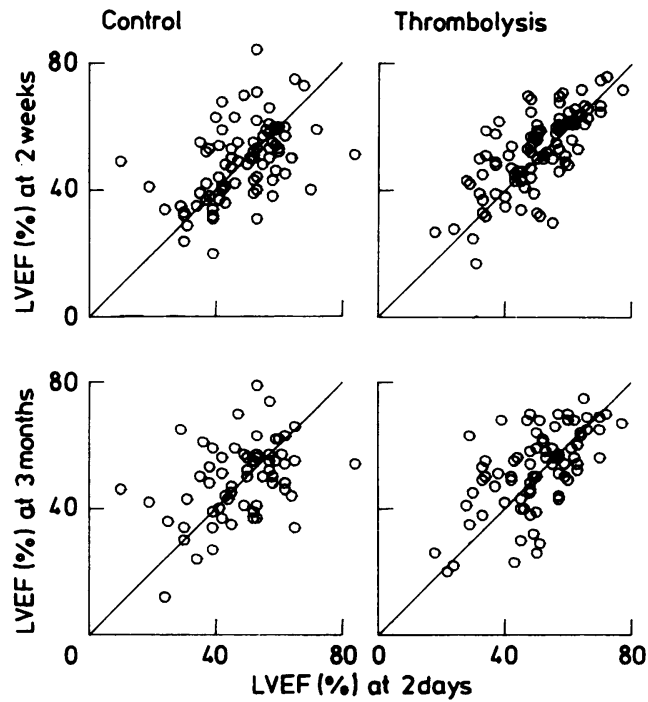

Fig 3 Paired analysis of left ventricular ejection fraction ( $L V E F$ ) at 2 days versus 2 weeks (top) and at 2 days versus 3 months (bottom) in patients with inferior wall infarction allocated to thrombolytic treatment and in controls. The line of identity is drawn in each diagram. Note a small improvement in LVEF between 2 days and 2 weeks after thrombolytic treatment. 
Table 4 Left ventricular ejection fraction in patients allocated to thrombolytic treatment in relation to the results of the intervention and infarct site

\begin{tabular}{lll}
\hline Anterior & \multicolumn{2}{l}{ Inferior } \\
\cline { 2 - 3 } $\operatorname{Noan}(S D)$ & No Mean $(S D)$ \\
\hline
\end{tabular}

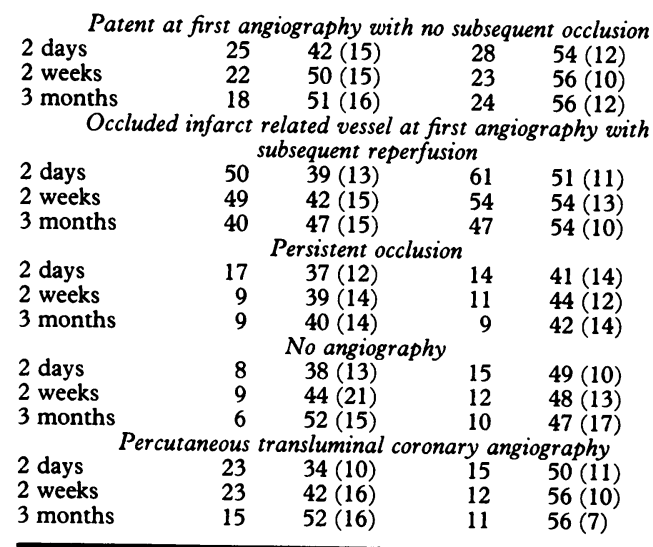

See footnotes to tables 1 and 2. A subset of patients underwent immediate percutaneous transluminal coronary angiography; these are presented separately but have also been included in the other groupings.

ejection fraction was seen mainly in patients with anterior wall infarction and an open infarct related vessel at angiography and those who showed reperfusion (tables 4 and 5). Ejection fractions were most improved in patients who had percutaneous transluminal coronary angioplasty immediately after thrombolysis both in anterior and in inferior wall infarction (table 5). We also saw a non-significant improvement in global left ventricular ejection fraction in patients with a persistent occlusion despite thrombolysis. But the number of patients in this group was too small for a conclusion to be reached.

Differences between the two treatment groups were similar in patients admitted before and after January 1984. Thus the more prompt thrombolysis achieved by pretreatment with intravenous streptokinase had no apparent effect on global ejection fraction.

During the three months between admission and the third radionuclide angiographic study myocardial infarction was less frequent in the control group. There were 13 reinfarctions in the control group (four anterior and nine inferior) compared with 25 patients ( 5 anterior and 20 inferior) in the thrombolysis group. In 35 out of these 38 patients reinfarction occurred in the same myocardial area as the index infarction. Despite reinfarction, global left ventricular function did not change between two weeks and three months in the 25 patients allocated to thrombolytic treatment (mean change in ejection fraction $0.5 \%$ ), while there was $13.2 \%$ loss in ejection fraction in the conventionally treated patients.

\section{Discussion}

Earlier reports of this trial indicate that thrombolysis reduces the infarct size, as determined by myocardial enzyme concentrations ${ }^{9}$; preserves global and regional left ventricular function, as measured by contrast angiography ${ }^{10}$; and improves survival. ${ }^{8}$ The present analysis shows that preservation of global left ventricular function was already apparent two days after admission, became more prominent at two weeks, and persisted throughout the

Table 5 Change in left ventricular ejection fraction $(\triangle E F)$ in 269 patients allocated to thrombolysis according to the patency of the vessel and attempted percutaneous transluminal angiography

\begin{tabular}{|c|c|c|c|c|c|c|}
\hline & \multicolumn{3}{|c|}{ Anterior } & \multicolumn{3}{|c|}{ Inferior } \\
\hline & No & $\operatorname{Mean}(S D)$ & $p$ & No & Mean $(S D)$ & $p$ \\
\hline \multicolumn{7}{|c|}{ Patent at first angiography with no subsequent occlusion } \\
\hline$\triangle E_{1}$ & 18 & $9 \cdot 0(10 \cdot 3)$ & 0.002 & 21 & $1 \cdot 5(6 \cdot 3)$ & NS \\
\hline$\triangle \mathrm{EF} 2$ & 14 & $8 \cdot 4(14 \cdot 1)$ & 0.04 & 20 & $3.2(10 \cdot 4)$ & NS \\
\hline \multicolumn{7}{|c|}{ Occluded infarct related vessel at first angiography with subsequent reperfusion } \\
\hline$\triangle \mathrm{EF} 1$ & 39 & $2 \cdot 5(8 \cdot 0)$ & 0.06 & 48 & $3.7(9 \cdot 8)$ & 0.01 \\
\hline \multirow{2}{*}{\multicolumn{7}{|c|}{ Persistent occlusion }} \\
\hline$\triangle \mathrm{EF} 1$ & 9 & & & & $2.2(7.9)$ & NS \\
\hline$\triangle \mathrm{EF} 2$ & 9 & $3.3(13.9)$ & NS & 9 & $2 \cdot 8(11.0)$ & NS \\
\hline \multicolumn{7}{|c|}{ No angiography } \\
\hline \multirow{2}{*}{\multicolumn{7}{|c|}{$\begin{array}{c}13.7(12 \cdot 5) \\
\text { Percutaneous transluminal angioplasty }\end{array}$}} \\
\hline & & & & & & \\
\hline$\triangle \mathrm{EF}_{1}$ & 17 & $7 \cdot 6(8 \cdot 5)$ & 0.002 & 10 & $9 \cdot 3(7.9)$ & 0.005 \\
\hline$\triangle \mathrm{EF} 2$ & 12 & $9 \cdot 7(14.5)$ & 0.04 & 9 & $8.6(9.9)$ & 0.03 \\
\hline
\end{tabular}

Paired analysis of changes in left ventricular ejection fraction in the same patients as table 4. 
three month observation period. The mean left ventricular ejection fraction in conventionally treated patients did not change between two days and three months after admission.

The improvement of global left ventricular ejection fraction measured by gated equilibrium radionuclide angiography was greater in patients with anterior myocardial infarction than in patients with inferior infarction. In patients with anterior wall infarction global left ventricular ejection fractions were $9 \%$ higher after two weeks in patients allocated to thrombolytic treatment than in patients treated conventionally. This resembles the $7 \%$ difference (50 (13)\% and $43(14) \%$ respectively) measured by contrast angiography in the same study. ${ }^{10}$ In patients with inferior myocardial infarction the difference between the two treatment groups was smaller by radionuclide angiography than by contrast angiography (8\%). This is probably the result of photon attenuation of technetium-99m in the body. ${ }^{2122}$ This attenuation causes volume changes close to the chest wall to be more strongly represented in the scintigraphic images than volume changes in the inferoposterior region of the left ventricle.

At two weeks both radionuclide angiography and contrast angiography showed that patients with an open infarct related artery at admission had the highest left ventricular ejection fractions, those with successful recanalisation had lower fractions, and patients with persistent occlusion had the lowest fractions. Since left ventricular pressure measurements and heart rate were the same in both treatment groups salvage of myocardial cells must be responsible for the improvement in ejection fraction.

Radionuclide angiograms obtained between one and three days after admission indicate that part of the improvement in left ventricular function after thrombolysis has already occurred. There was a further improvement up to two weeks after admission in patients allocated to thrombolysis, but no further change between 2 weeks and 3 months. This suggests that recovery of myocardial function after prolonged ischaemia was complete at two weeks. ${ }^{23}$ Echocardiographic studies have shown a similar progressive improvement in the first ten days. ${ }^{24}$ In future studies on the effect of thrombolytic treatment measurements of left ventricular function obtained after approximately two weeks will be adequate and little if any knowledge will be gained by restudy after a longer interval.

Unlike several other studies we did not measure left ventricular function at randomisation. This was because we did not want to delay the start of thrombolytic treatment. Because the distributions of all other baseline data between the two treatment groups were similar it is unlikely that baseline differences in left ventricular function or in haemodynamic state will account for the differences measured in the first few days of infarction.

Because patients died before radionuclide angiograms could be obtained or refused to undergo further investigations data were missed from this study. Data on patients who had bypass surgery or percutaneous transluminal coronary angiography elsewhere were also missed. It is unlikely, however, that the differences between conventionally treated patients and those allocated to thrombolysis are the result of selection bias. Baseline data in patients with and without follow up radionuclide angiograms were similar and the results of independent enzymatic measurements of infarct size were similar in patients allocated to thrombolysis and controls with and without radionuclide angiography (table 1).

Most other randomised studies of intracoronary thrombolysis have not shown an effect on global left ventricular ejection fraction. ${ }^{124-625}$ This is due in part to the small number of patients studied and probably to the long interval between onset of symptoms and thrombolytic treatment in most other studies. In the present study the interval was only 195 minutes (median), whereas it was 276 minutes in the Western Washington Trial which included 250 patients, 100 of whom underwent radionuclide angiography. ${ }^{25}$ One other randomised trial of 50 patients did show preservation of global left ventricular function after intracoronary thrombolytic treatment. ${ }^{3}$ Mean treatment delay in that study was 240 minutes, and these workers also reported data on myocardial enzyme release that are compatible with a $40 \%$ reduction of myocardial infarct size. ${ }^{8}$ The initial response to intracoronary treatment with streptokinase within the first few hours after the onset of myocardial infarction was cautious, ${ }^{26}$ but we believe that now there is sufficient evidence to prove that this treatment preserves global and regional left ventricular function and improves survival. The preservation of the left ventricular function persists for at least three months despite the higher rate of recurrent myocardial infarction after thrombolysis. Further studies should define the subgroups of patients that are most likely to benefit from this intervention. Furthermore, studies should be performed to compare the effects of different methods of thrombolysis-such as intravenous administration of streptokinase, intravenous infusion of acetylated streptokinase-plasminogen complex, or tissue plasminogen activator and intracoronary streptokinase-that can if necessary be followed by immediate mechanical perforation and percutaneous transluminal coronary angioplasty. 


\section{References}

1 Rentrop KP, Feit F, Blanke $\mathrm{H}$, et al. Effects of intracoronary streptokinase and intracoronary nitroglycerin infusion on coronary angiographic patterns and mortality in patients with acute myocardial infarction. $N$ Engl f Med 1984;311:1457-63.

2 Khaja F, Walton JA Jr, Brymer JF, et al. Intracoronary fibrinolytic therapy in acute myocardial infarction. Report of a prospective randomized trial. $N \mathrm{Engl} \mathrm{f}$ Med 1983;308:1305-11.

3 Anderson JL, Marshall HW, Bray BE, et al. A randomized trial of intracoronary streptokinase in the treatment of acute myocardial infarction. $N$ Engl $\mathcal{F}$ Med 1983;308:1312-8.

4 Kennedy JW, Ritchie JL, Davis KB, Fritz JK. Western Washington randomized trial of intracoronary streptokinase in acute myocardial infarction. $N$ Engl $\mathcal{f}$ Med 1983;309:1477-82.

5 Leiboff RH, Katz RJ, Wasserman AG, et al. A randomized, angiographically controlled trial of intracoronary streptokinase in acute myocardial infarction. $A m \mathcal{F}$ Cardiol 1984;53:404-7.

6 Raizner AE, Tortoledo FA, Verani MS, v Reet RE. Intracoronary thrombolytic therapy in acute myocardial infarction: a prospective, randomized controlled trial. Am f Cardiol 1985;55:301-8.

7 Rentrop P. Thrombolytic therapy in patients with acute myocardial infarction. Circulation 1985;71:627-31

8 Simoons ML, Serruys PW, van den Brand M, et al. Improved survival after early thrombolysis in acute myocardial infarction: a randomized trial conducted by the Interuniversity Cardiology Institute in the Netherlands. Lancet 1985;ii:578-82.

9 Simoons ML, Serruys PW, van den Brand M, et al. Early thrombolysis in acute myocardial infarction: limitation of infarct size and improved survival. $\mathcal{f ~} \mathrm{Am}$ Coll Cardiol 1986;7:717-28.

10 Serruys PW, Simoons ML, Suryapranata H, et al. Preservation of global and regional left ventricular function after early thrombolysis in acute myocardial infarction. $\mathcal{F} \mathrm{Am}$ Coll Cardiol 1986;7:729-42.

11 Fioretti P, Simoons ML, Serruys PW, et al. Clinical course after attempted thrombolysis in myocardial infarction. Eur Heart $\mathcal{f}$ 1982;3:422-32.

12 Serruys PW, van den Brand M, Hooghoudt TEH, et al. Coronary recanalization in acute myocardial infarction: immediate results and potential risks. Eur Heart $\mathcal{f}$ 1982;3:404-15.

13 Zelen $M$. A new design for randomized clinical trials. $N$ Engl f Med 1979;300:1242-3.

14 Rogers WJ, Mantle JA, Hood WP, et al. Prospective randomized trial of intravenous and intracoronary streptokinase in acute myocardial infarction. Circulation 1983;68:1051-61.

15 Schroder R, Biamino G, Leitner ER, et al. Intravenous short-term infusion of streptokinase in acute myocardial infarction. Circulation 1983;67:536-48.

16 Simoons ML, Serruys PW, Fioretti P, van den Brand M, Hugenholtz PG. Practical guidelines for treatment with beta-blockers and nitrates in patients with acute myocardial infarction. Eur Heart $\mathfrak{f}$ 1983;4:120-35.

17 Verheugt FWA, van Eenige MJ, Res JCJ, et al. Bleeding complications of intracoronary fibrinolytic therapy in acute myocardial infarction: assessment of risk in a randomized trial. Br Heart $\mathcal{F} 1985 ; 54: 455-9$.

18 Reiber JHC, Lie SP, Simoons ML, et al. Clinical validation of fully automated computation of ejection fraction from gated equilibrium bloodpool scintigrams. f Nucl Med 1983;24:1099-107.

19 Braat S, Brugada P, De Zwaan C, Den Dulk K, Wellens $H$. Right and left ventricular ejection fraction in acute inferior wall infarction with or without ST segment elevation in lead V4R. $\mathcal{F} \mathrm{Am}$ Coll Cardiol 1984;5:940-4.

20 Laarse A vd, Vermeer F, Hermens WT, et al. Effects of early intracoronary streptokinase on infarct size estimated from cumulative enzyme release and on enzyme release rate. A randomised trial of 533 patients with acute myocardial infarction. $\mathrm{Am}$ Heart $\mathcal{F}$ (in press).

21 Wackers FJT. Characteristics of radiopharmaceuticals in nuclear cardiology. Implications for practical cardiac imaging. In: Simoons ML, Reiber JHC, eds. Nuclear imaging in clinical cardiology. The Hague: Martinus Nijhoff, 1984:19-37.

22 Yeh E-L, Yeh Y-S. Theoretical error in radionuclide ejection fraction study due to photon attenuation. Eur $\mathcal{F}$ Nucl Med 1981;6:69-71.

23 Braunwald E, Kloner RA. The stunned myocardium; prolonged, postischemic ventricular dysfunction. Circulation 1982;66:1146-9.

24 Charuzi Y, Beeder C, Marshall LA, et al. Improvement in regional and global left ventricular function after intracoronary thrombolysis: assessment with twodimensional echocardiography. Am $\mathcal{F}$ Cardiol 1984;53:662-5.

25 Ritchie JL, Davis KB, Williams DL, Caldwell J, Kennedy JW. Global and regional left ventricular function and tomographic radionuclide perfusion: The Western Washington intracoronary streptokinase in myocardial infarction trial. Circulation 1984;70:867-75.

26 Hugenholtz PG, Rentrop P. Thrombolytic therapy for acute myocardial infarction: quo vadis? Eur Heart $\mathcal{f}$ 1982;3:395-403. 